\title{
Prevalence of multiple sclerosis in Rochdale
}

\author{
David I Shepherd, Alison Summers
}

\begin{abstract}
The prevalence of multiple sclerosis in the Rochdale Metropolitan Borough in the north east of Greater Manchester has been established.

Case ascertainment was partly prospective via a neurological register from 1979 and by contact with general practitioners, therapists, and social services.

On prevalence day, 1 January 1989, 254 patients with multiple sclerosis were living in Rochdale. The overall prevalence was $122 / 100000$ population and $96 / 100000$ population for probable cases only. The peak rate for women aged 35 to 44 years was $437 / 100000$ population and for men aged 45 to 54 years 221/100 000. Familial multiple scleresis was present in $10.8 \%$ of fämilies.

In this, the first study in north west England, the prevalence of multiple sclerosis in Rochdale is similar to that in southern England and Wales but lower than that in Scotland.
\end{abstract}

(F Neurol Neurosurg Psychiatry 1996;61:415-417)

Keywords: multiple sclerosis; prevalence; Rochdale

Multiple sclerosis remains a common neurological disorder in the United Kingdom, the highest prevalence recorded in the world occurring in Orkney and Shetland. ${ }^{1}$ Earlier studies have suggested a significantly higher prevalence in Scotland compared with England $^{2-6}$ but more recent studies in south Wales, Southampton, Cambridge, south east London, and Sussex have shown prevalence rates in the range $106-125 / 100000$ population, thus indicating that the difference is less than previously thought..$^{7-11}$

Multiple sclerosis comprised $2 \cdot 7 \%$ of admissions for neurological disorders to Manchester Royal Infirmary at the turn of the century. ${ }^{12}$ However, no prevalence study of the disease has been conducted in the north west region of England and there are no studies anywhere in the north of England which provide data suitable for comparison with recent surveys in other parts of the United Kingdom. The current study is an analysis of the preva- lence of multiple sclerosis in Rochdale. We report the basic epidemiological findings.

\section{Study area}

The population surveyed was the resident population of Rochdale Metropolitan Borough in the north east of Greater Manchester. The district's 20 political wards cover the three towns of Rochdale, Middleton, and Heywood and the more rural areas of Littleborough, Milnrow, and Wardle. The 1989 mid-year population estimate was $207600 .^{13}$

\section{Patients and methods}

The approval of the district ethics committee was obtained. We sought to establish the point prevalence of multiple sclerosis in Rochdale on 1 January 1989. Since the appointment of one of us (DIS) in 1979 as neurologist responsible for Rochdale district, a diagnostic index of all neurology patients seen has been kept in the subregional neurological centre at North Manchester General Hospital. Further patients were located through identification by one of us (DIS) during the course of the study and through voluntary organisations, the Social Services register of disabled people, hospital activity analysis, and other health service sources (notably occupational therapists, speech therapists, chiropodists), and the younger disabled unit. Residents with multiple sclerosis in the Leonard Cheshire Home were only accepted if their previous residence was within the study area. These accumulated data were then sent to the appropriate general practitioner who identified some additional patients and indicated who was alive and living in the area on prevalence day, 1 January 1989. A proforma was established for each patient and in many cases adequate data were obtained from the existing neurological records. All general practices were visited and additional information obtained, when relevant, from 90 patients' records. A few patients were visited in their homes with the permission of the general practitioner.

Classification was according to Allison and Miller $^{14}$ and the Poser diagnostic criteria but without adherence to the upper age limit of 59 in the second. ${ }^{15}$ To allow comparison of prevalence in populations with different age and sex 
Table 1 Prevalence of multiple sclerosis in Rochdale

\begin{tabular}{lcl}
\hline Category & Number $(\%)$ & $\begin{array}{l}\text { Prevalence } / 10^{5} \\
(95 \% \text { confidence interval })\end{array}$ \\
\hline Alison and Miller & & \\
$\quad$ Probable & $199(78 \cdot 3)$ & $95 \cdot 9(83-109)$ \\
Possible & $55(21 \cdot 7)$ & $26 \cdot 5(20-34)$ \\
Poser $e t$ al ${ }^{15}$ & $138(54 \cdot 3)$ & $66 \cdot 5(55-78)$ \\
CDMS & $29(11 \cdot 4)$ & $14 \cdot 0(9-19)$ \\
LSDMS & $65(25 \cdot 6)$ & $31 \cdot 3(24-39)$ \\
CPMS & 0 & 0 \\
LSPMS & $22(8 \cdot 7)$ & $10 \cdot 6(6-15)$ \\
Suspected & $254(100)$ & $122 \cdot 4(107-138)$ \\
Total & &
\end{tabular}

Age distribution by sex of patients with multiple sclerosis.

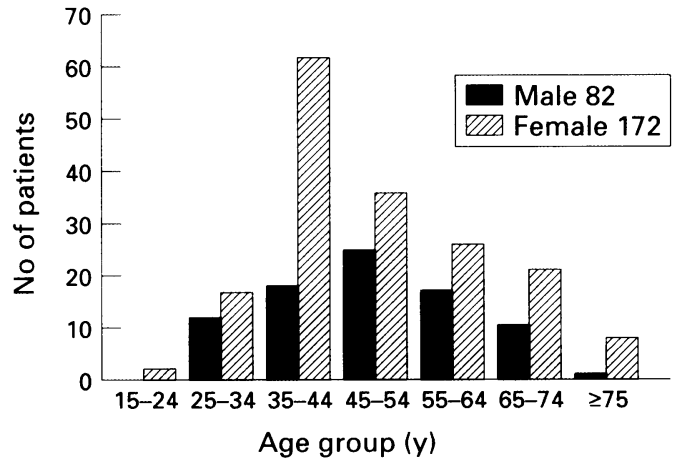

structures, a standardised prevalance ratio was calculated with the indirect method using Northern Ireland 1961 prevalence figures. ${ }^{16}$ The National Health Service (NHS) number was obtained for every patient from Rochdale Health Authority notes, medical records held by the general practitioners, or via the local medical committee. Eventually, all patients in the current study were "flagged" in the NHS central register.

\section{Results}

On prevalence day, 1 January 1989, 254 patients with multiple sclerosis were living in Rochdale. Seventy nine per cent of prevalent patients were identified through the neurology department, with the other important sources being general practitioners $(31 \%)$ and the Social Services register (14\%). Eighty seven per cent of patients could have been identified using the neurology department and the general practitioners as sole sources. Of the total 254 patients, $216(85 \%)$ had been seen personally and investigated by one of us (DIS) or by a neurological colleague, $18(7 \%)$ had been seen by a neurologist elsewhere, and the remaining $20(8 \%)$ by general physicians. The overall prevalence was $122 / 100000$ population and 96/100 000 population for probable cases alone. Table 1 shows the breakdown of cases by diagnostic group according to Allison and Miller $^{14}$ and Poser et al. ${ }^{15}$ As in other series, ${ }^{7-9}$ a small proportion of possible cases in the Allison and Miller ${ }^{14}$ classification cannot be classified by the criteria of Poser et $a l^{15}$ and therefore were given the designation suspected.

Mean age of onset was 35.0 years with three patients commencing before the age of 15 and two after 65 years. Mean duration of the disease on prevalence day was 13.9 years with minimal sex variation (women 14.0 years, men 13.8 years) and the maximum duration was 51 years. The figure shows the age distribution by sex on prevalence day. The course of the disease was progressive in 50 patients $(19.7 \%)$ and relapsing/remitting initially in 190 patients $(74.8 \%)$. In six patients the course of the disease was uncertain and eight patients had had only a single clinical episode. In 187 of the 190 relapsing/remitting patients the time to first relapse was known, the mean being 4.6 years and the maximum 26 years. There were 172 women in the study and female to male ratio was 2 to 1 . The overall female prevalence rate was $162 / 100000$ population and the male $82 / 100000$ population. The age and sex specific prevalence rates for Rochdale show a peak rate for men of $221 / 100000$ population at ages 45 to 54 and for women of $437 /$ 100000 at ages 35 to 44 years. Thus on prevalence day, one in every 229 women aged 35 to 44 years had multiple sclerosis.

Annual incidence rates calculated from date of onset of the disease in the 254 prevalent patients were $5 \cdot 4 / 100000$ during the most recent five year period and $5 \cdot 4,4 \cdot 3,4 \cdot 1$, and $2 \cdot 4 / 100000$ during the four previous five year periods (with the most recent quoted first).

Table 2 provides a summary of the findings in the present survey in comparison with eight previous prevalence surveys in large population areas in the United Kingdom over the past 20 years. For the purposes of comparison, the early probable and latent group in the first north east Scotland survey ${ }^{2}$ has been combined with the probable group. The standardised prevalence ratio (SPR) allows comparison between surveys in populations which have different age/sex distributions.

Table 2 Comparison of UK surveys of multiple sclerosis

\begin{tabular}{|c|c|c|c|c|c|c|c|c|c|}
\hline & $\begin{array}{l}\text { NE Scotland } \\
1970^{2}\end{array}$ & $\begin{array}{l}\text { NE Scotland } \\
1980^{+}\end{array}$ & $\begin{array}{l}\text { SE Wales } \\
1985\end{array}$ & $\begin{array}{l}\text { Cambridge } \\
1990^{\circ}\end{array}$ & $\begin{array}{l}\text { Cambridge } \\
1993^{\prime 4}\end{array}$ & $\begin{array}{l}\text { Sutton } \\
1985^{\prime \prime}\end{array}$ & $\begin{array}{l}\text { Southampton } \\
1987^{\star}\end{array}$ & $\begin{array}{l}\text { Sussex } \\
1991^{\prime \prime}\end{array}$ & $\begin{array}{l}\text { Rochdale } \\
1989\end{array}$ \\
\hline Cases & 557 & 839 & 441 & 374 & 441 & 195 & 411 & 810 & 254 \\
\hline Population & 440176 & 471000 & 376718 & 288410 & 290700 & 170000 & 417000 & 596594 & 207600 \\
\hline Prevalence & 127 & 178 & & 130 & 152 & 115 & & 136 & 122 \\
\hline$(/ 100000)$ & $(116-137)$ & $(166-191)$ & $(107-129)$ & $(117-144)$ & $(139-167)$ & $(100-132)$ & $(90-109)$ & $(127-145)$ & $(107-138)$ \\
\hline Probable cases & 105 & 145 & & & 120 & 104 & & 120 & \\
\hline$(/ 100000)$ & $(96-115)$ & $(134-156)$ & $(75-94)$ & $(96-120)$ & $(108-133)$ & $(89-120)$ & $(83-102)$ & $(108-133)$ & $(83-109)$ \\
\hline SPR & $\begin{array}{l}153 \\
(140-166)\end{array}$ & $\begin{array}{l}221 \\
(184-261)\end{array}$ & $\begin{array}{l}139 \\
(126-150)\end{array}$ & $\begin{array}{l}121 \\
(108-133)\end{array}$ & $\begin{array}{l}142 \\
(129-157)\end{array}$ & $\begin{array}{l}129 \\
(111-147)\end{array}$ & $\begin{array}{l}115 \\
(104-127)\end{array}$ & - & $\begin{array}{l}143 \\
(126-161)\end{array}$ \\
\hline Mean age & $48 \cdot 2$ & $45 \cdot 1$ & 48.7 & $49 \cdot 2$ & - & $49 \cdot 0$ & $48 \cdot 6$ & $48 \cdot 6$ & 48.9 \\
\hline Mean age of onset & $34 \cdot 2$ & 34.5 & $32 \cdot 2$ & $29 \cdot 6$ & $\ldots$ & $34 \cdot 1$ & $32 \cdot 6$ & $33 \cdot 1$ & $35 \cdot 0$ \\
\hline Mean duration & $14 \cdot 4$ & $14 \cdot 8$ & $16 \cdot 5$ & $19 \cdot 2$ & - & $15 \cdot 4$ & $15 \cdot 7$ & $15 \cdot 5$ & $13 \cdot 9$ \\
\hline Sex ratio $(F: M)$ & 1.6 & 1.9 & $2 \cdot 0$ & $2 \cdot 5$ & - & $2 \cdot 3$ & $2 \cdot 1$ & $2 \cdot 5$ & $2 \cdot 1$ \\
\hline Annual incidence & $5 \cdot 3$ & $7 \cdot 2$ & $5 \cdot 4$ & 5.9 & - & $5 \cdot 0$ & $4 \cdot 7$ & $5 \cdot 0$ & $5 \cdot 4$ \\
\hline$(100000)$ & $(1959-73)$ & $(1977-80)$ & $(1947-84)$ & $(1990-1)$ & - & $(1974-84)$ & $(1976-82)$ & $(1978-84)$ & $(1979-88)$ \\
\hline
\end{tabular}

SPR = standardised prevalence ratio using Northern Ireland $1961^{16}$ as standard population

Values in parentheses are $95 \%$ CIs, except annual incidence, which are dates. 
Twenty seven patients in the study had another first degree relative affected and in four instances, the second relative was in this survey. There were eight instances of parent/child relationship and nine of affected siblings. In three families more than one relative was affected; thus $10 \cdot 8 \%$ of families (27 out of 250) had a positive family history. In this survey 122 patients $(48 \cdot 2 \%)$ were born within the study area, a further $84(33 \cdot 2 \%)$ within the north west of England, and only five were born outside the United Kingdom.

\section{Discussion}

We think that our estimate of prevalence is unlikely to be increased by resurveying. Firstly, this was predominantly a prospective study based on the planned accumulation of data on all patients (inpatients and outpatients, ward referrals, domiciliary, and private patients) by one of us (DIS) from 1979 and secondly, over the succeeding three years, we have only located a further 11 patients who diagnostically would have been eligible for inclusion on 1 January 1989.

In Rochdale the mean age of onset was slightly later and the mean duration slightly shorter than in other comparable surveys (table 2). The incidence estimate for Rochdale was comparable with those for other surveys in England and Wales. The familial occurrence of $10.8 \%$ exceeded the figure of $9.8 \%$ for the second north east Scotland study ${ }^{17}$ but is less than the $17 \%$ recorded in a Canadian study. ${ }^{18}$

Repeating prevalence studies in the same population in north east Scotland ${ }^{34}$ and in Cambridge ${ }^{19}$ has shown a higher prevalence on resurveying. Explanations proposed include improved case ascertainment, changes in survey methodology, and changes in the population age structure. In south east Wales, however, a second prevalence study after three years did not show an increase in prevalence. ${ }^{20}$

The difference in prevalence of multiple sclerosis between Scotland and other parts of the United Kingdom is well known. Evidence from mortality statistics suggests that this gradient may be declining. ${ }^{21}$ The standardised prevalence ratio (SPR) provides the most appropriate means of comparing surveys in different populations. Using this measure, the prevalence estimate for Rochdale (143) is similar to those obtained in south east Wales and in the second Cambridge survey-in other words, similar to the highest estimates obtained from surveys in the southern part of the United Kingdom. There is no significant difference between the SPR for Rochdale and the SPR for the southern United Kingdom surveys.

We conclude that this first study in north west England shows the prevalence of multiple sclerosis to be similar to that in southern England and Wales but lower than that in Scotland.

1 Poskanzer DC, Walker AM, Yonkondy J, et al. Studies in the epidemiology of multiple sclerosis in the Orkney and Shetland islands. Neurology 1976;26:14-7.

2 Shepherd DI, Downie AW. Prevalence of multiple sclerosis in north-east Scotland. BMF 1978;ii:314-6.

3 Shepherd DI, Downie AW. A further prevalence study of multiple sclerosis in north-east Scotland. $f$ Neurol Neurosurg Psychiatry 1980;43:310-5.

4 Phadke JG, Downie AW. Epidemiology of multiple sclerosis in the north-east (Grampian Region) of Scotland-an update. $\mathcal{F}$ Epidemiol Community Health 1987;41:5-13.

5 Poskanzer DC, Schapira K, Miller H. Epidemiology of multiple sclerosis in the counties of Northumberland and Durham. F Neurol Neurosurg Psychiatry 1963;26:368-76.

6 Brewis M, Poskanzer DC, Rolland C, et al. Neurological disease in an English city. Acta Neurol Scand 1966;42 disease in an E

7 Swingler RJ, Compston DAS. The prevalence of multiple sclerosis in south east Wales. $f$ Neurol Neurosurg Psychiatry 1988;51:1520-4.

8 Roberts MHW, Martin JP, McLellan DL, et al. The prevalence of multiple sclerosis in the Southampton and South West Hampshire Health Authority. $\mathcal{F}$ Neurol Neurosurg Psychiatry 1991;54:55-9.

9 Mumford CJ, Fraser MB, Wood NW, et al. Multiple sclerosis in the Cambridge health district of East Anglia. 7 Neurol Neurosurg Psychiatry 1992;55:877-82.

10 Williams ES, McKeran RO. Prevalence of multiple sclerosis in a south London borough. BMF 1986;ii:237-9.

11 Rice Oxley M, Williams ES, Rees JE. A prevalence study of multiple sclerosis in Sussex. $\mathcal{F}$ Neurol Neurosurg Psychiatry 1995;58:27-30.

12 Williamson RT. Med Chron 1903;37:261-73.

13 Office of Population Censuses and Surveys. OPCS Monitor. Extrapolated population estimates for mid-1989 and 1990. Extrapolated population

14 Allison RS, Millar JHD. Prevalence and familial incidence of disseminated sclerosis. Ulster Med F 1954;23 (suppl 2): 5-27

15 Poser CM, Paty DW, Scheinberg L, et al. New diagnostic criteria for multiple sclerosis: guidelines for research protocols. Ann Neurol 1983;13:227-31.

16 Millar JHD. Multiple sclerosis in Northern Ireland. In: Clifford Rose F, ed. Clinical neuroepidemiology. Tunbridg Wells: Pitman Medical, 1980:222-7.

17 Shepherd DI. Multiple sclerosis in north-east Scotland. In Clifford Rose F, ed. Clinical neuroepidemiology. Tunbridge Wells: Pitman Medical, 1980:196-207.

18 Hader WJ, Elliot M, Ebers GC. Epidemiology of multiple sclerosis in London and Middlesex County, Ontario, Canada. Neurology 1988;38:617-21.

19 Robertson N, Compston DAS. Surveying multiple sclerosis in the United Kingdom. I Neurol Neurosurg Psychiatry 1995;58:2-6.

20 Hennessy A, Swingler RJ, Compston DAS. The incidence and mortality of multiple sclerosis in south east Wales. $\mathcal{F}$ Neurol Neurosurg Psychiatry 1989;52:1085-9.

21 Williams ES, Jones DR, McKeran RO. Mortality rates from multiple sclerosis: geographical and temporal variations revisited. F Neurol Neurosurg Psychiatry 1991;54: $104-9$. 